\title{
The Rivermead head injury follow up questionnaire: a study of a new rating scale and other measures to evaluate outcome after head injury
}

\author{
S Crawford, F J Wenden, D T Wade
}

\begin{abstract}
Objective-To develop and evaluate a short (10 item) simple measure of outcome mainly for use with patients with mild to moderate head injuries.

Design-Two studies on patients at three and six months after injury, comparing different methods of administration (two raters and postal questionnaire), and comparing ratings with other assessments.
\end{abstract}

Subjects-Forty three patients seen three months after injury and 46 seen six months after injury: both groups had head injuries covering a range of severity from minor to severe.

Main outcome measures-Differences between ratings in different groups of patients (Mann-Whitney $U$ test); differences in ratings using different methods of administration (Wilcoxon signed rank test); and correlations between ratings from the same patient (Spearman $r$ ).

Results-The sum total ratings were consistent between raters and between methods (postal questionnaire $v$ face to face interview) with no evidence of selective bias between raters or methods. Ratings on individual items were also reasonably consistent. The sum total ratings varied as anticipated between groups divided by clinical judgement of recovery and patient assessment of recovery, and related as expected to the extent of post-concussion symptomatology. The 10 items included covered the most important problem areas reported by patients.

Conclusion-The Rivermead head injury follow up questionnaire (RHFUQ) is a short, simple, adequately reliable, and valid measure of outcome, across the entire range of severity, but particularly after mild to moderate head injury.

\section{(F Neurol Neurosurg Psychiatry 1996;60:510-514)}

Oxford Head Injury Service, Rivermead Rehabilitation Centre, Abingdon Road Oxford, OX1 4XD, UK S Crawford F J Wenden D T Wade

Correspondence to: Mrs Crawford.

Received 13 February 1995 and in final revised Accepted 12 January 1996 and in final revised form form of information, advice, and support, given between seven and 10 days after injury. The service aimed to register and follow up all the population with head injuries in Oxfordshire between the ages of 16 and 65 .

To evaluate functional and social outcomes (at the level of disability), a short and simple measure which would be straightforward to use and to analyse was needed. ${ }^{3}$ Most published measures are only applicable to patients with severe injury. Previous studies have concentrated on neuropsychological and postconcussion symptoms, or antisocial behaviour, using various measures, most often batteries of psychometric assessments, which can be very time consuming. ${ }^{359}$ Others have used structured interviews and questionnaires, often with rating scales. ${ }^{10-13}$

As existing questionnaires were considered inappropriate across the whole range of severity of head injury, the OXHIS designed two complementary measures to evaluate outcomes. The Rivermead postconcussion symptom questionnaire (RPQ), which uses a five point rating scale, is described elsewhere. ${ }^{1415}$ The Rivermead head injury follow up questionnaire (RHFUQ), described here, was devised erence to published measures used in cases of minor head injury. ${ }^{3}$ It comprises a set of 10 brief questions with subjective ratings of outcome in terms of work, relationships, and social, leisure, and domestic activities.

The use of the questionnaire was piloted and, after minor modifications (see appendix), a further investigation of its reliability was undertaken as part of a preliminary study of patient outcome at six months after head injury. This paper describes and discusses the questionnaire's reliability and some analyses which investigate its validity.

\section{Methods}

PATIENTS

All patients were taken from the early development stage of the OXHIS register. The working definition of head injury used was: any blow to the head, clinically diagnosed as "head injury", even if insufficient to cause loss of consciousness, whether or not other injuries were also sustained. All patients had been admitted to hospital.

Patients for follow up were approached by letter, having been randomly allocated between two therapists for initial contact. This on the basis of clinical experience and with ref-

\section{PROCEDURE} of providing an early follow up service in the head injury may be $250-300$ per 100000 in Britain. ${ }^{12}$ The majority of patients will have had minor head injuries, but little is known about the extent or the nature of any consequences. ${ }^{34}$ The Oxford Head Injury Service

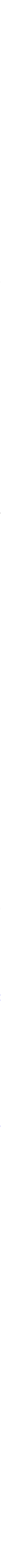


reminded them of the purpose of the study and asked whether they were willing to be interviewed.

At the initial follow up three months after injury, the letter included a copy of the follow up questionnaire (RHFUQ), which patients were asked to complete but not return. When they were visited by the first therapist the posted questionnaires were collected, but not examined by the therapist, who then administered the same questionnaire, clarifying any queries. At the second interview, the questionnaire was administered by the other therapist. The therapists also discussed any persisting problems with the patients, offering information, advice, and support. To minimise bias, the therapists did not discuss the results of the questionnaires, any problems, or planned intervention until both had completed their interviews.

At six month follow up the same general procedure was followed with both therapists administering the RHFUQ, but with the following differences: there was no postal version of the RHFUQ; the Rivermead postconcussion symptom questionnaire (RPQ) ${ }^{14}{ }^{15}$ was administered at both interviews before the RHFUQ; and, at the initial interview, the therapist completed a data sheet of basic epidemiological information.

At the three month follow up, 154 patients (age range 16-65) had been registered after their admission to hospital between July 1992 and January 1993. Six were excluded from follow up: one was deceased, one was abroad, one had no fixed address, two were in prison, and one was severely physically disabled and with learning difficulties. A random two thirds $(n=97)$ were approached whereas the remaining third ( $n=51)$ were excluded to provide control patients for another study. Of those patients approached for follow up, 54 were either uncontactable, had moved, or were not able to complete the questionnaire three times. Patients willing to be interviewed twice $(n=43)$ were seen by both therapists at an interval of about one week (mean eight days, median seven days, range 4-22 days).

At the six month follow up, 120 patients (age range 16-64) had been registered between October 1992 and February 1993. Five were excluded: one had died, one was abroad, one had severe physical disabilities, one had learning difficulties, and there was one who had recently had contact with another member of the OXHIS team. The remaining 115 patients (including 22 who had been interviewed at three months) were approached. Of those patients approached for follow up, 69 were either uncontactable, had moved, or were not able to complete the questionnaire twice. Those patients interviewed twice $(n=46)$, were visited by both therapists at intervals of about one week, (mean nine days, median seven days, range 3-34 days).

\section{FOLLOW UP QUESTIONNAIRE}

The revised version of the questionnaire used at six month follow up (see appendix), omitted an initial question on recovery (which was then included in the basic data sheet). The rating scale remained $0-4$, but the patient was asked to rate the amount of change rather than the level of difficulty posed by each item. This alteration resulted from the therapists' clinical judgement after the interviews at three month follow up. At six month follow up the sum totals for each questionnaire were obtained by adding ratings of $1,2,3$, and 4 (indicating: no change but more difficult, changes mild, moderate, or severe), for the 10 core items (section (a)). Answers given for open ended items (section (b), "any other difficulties"), were analysed separately.

\section{Results}

The demographic data collected for the three month follow up showed the patients' (30 men, 13 women) age range to be 17-64 (mean 32 (SD 15)). As Glasgow coma scales were not available for most patients an indication of the severity of injury was taken from the duration of post-traumatic amnesia (PTA), as recorded 7-10 days after injury by other members of the OXHIS team $(n=31)$ or as estimated from clinical records $(n=12)$. Using the criteria suggested by Russell and Smith, ${ }^{16}$ two were classified as very severe (PTA > seven days), two as severe (PTA $\geqslant 24$ hours but $\leqslant$ seven days), 20 as moderate (PTA $\geqslant$ one hour, but $<24$ hours) and 19 as mild (PTA < one hour). Most injuries had arisen from road traffic accidents $(n=21)$, followed by incidents at work $(\mathrm{n}=6)$, incidents at home $(\mathrm{n}=3)$, horse riding $(\mathrm{n}=3)$, and assaults $(n=2)$; the "other" category $(n=8)$ included sports injuries and falls outside the home.

The demographic data collected for the six month follow up showed the patients' (31 men, 15 women) age range to be 17-64 (mean 34 (SD) 13)). The lowest PTA score reported by patients at either six month assessment was used to determine the severity of injury of the sample: 23 had mild head injuries (12 of these had no PTA), six moderate, nine severe, and two very severe. Six patients were unable to estimate the duration of their PTA: (two of these were estimated as mild, two as moderate, one as severe and one as very severe by the investigators). Road traffic accidents were the predominant cause of head injury $(\mathbf{n}=27)$, followed by incidents at work and assaults (both $\mathrm{n}=5$ ), accidents at home $(\mathrm{n}=4)$, horse riding accidents $(n=3)$, falls $(n=1)$, and sport accidents $(n=1)$.

The table shows that the sum total ratings were consistently rated at both three and six months after injury, regardless of whether the questionnaire was self administered or administered by the therapist and the figure shows this at six months. The table also shows that ratings for most individual items on the questionnaire were reliable at both three and six months after injury. At three month follow up the items with the least significant coefficients were those covering relationships, possibly because these were reported by very few patients. At six month follow up, the questions 
Spearman's rank correlation coefficient for each item on the questionnaire and sum total ratings; together with rank order at first interview in both studies

\begin{tabular}{|c|c|c|c|c|c|c|}
\hline & \multicolumn{4}{|c|}{$\begin{array}{l}\text { Study one } \\
3 \text { month } \\
\text { ( } 43 \text { patients) }\end{array}$} & \multicolumn{2}{|c|}{$\begin{array}{l}\text { Study two } \\
6 \text { month } \\
\text { (46 patients) }\end{array}$} \\
\hline & $A v B$ & $B v C$ & $A v C$ & $\begin{array}{l}\text { Rank } \\
\text { order B }\end{array}$ & $B v C$ & $\begin{array}{l}\text { Rank } \\
\text { order B }\end{array}$ \\
\hline $\begin{array}{l}\text { Conversation with one } \\
\text { person } \\
\text { Conversation with two or }\end{array}$ & $0 \cdot 70^{\star \star}$ & $0 \cdot 84^{\star \star}$ & $0 \cdot 59^{\star \star}$ & $7(5)$ & $0 \cdot 60^{\star \star}$ & $8(7)$ \\
\hline more people & $0 \cdot 88^{\star \star}$ & $0 \cdot 83^{\star \star}$ & $0 \cdot 76^{\star \star}$ & $5(8)$ & $0 \cdot 89^{\star \star}$ & $5(9)$ \\
\hline Routine domestic activities & $0 \cdot 71^{\star \star}$ & $0 \cdot 71^{\star \star}$ & $0.59^{\star \star}$ & $6(6)$ & $0 \cdot 50^{\star}$ & $7(8)$ \\
\hline Previous social activities & $0 \cdot 56^{\star}$ & $0 \cdot 38$ & $0 \cdot 60^{\star \star}$ & $4(10)$ & $0.69^{\star \star}$ & $4(12)$ \\
\hline Previous leisure activities & $0 \cdot 65^{\star \star}$ & $0.51^{\star}$ & $0 \cdot 33$ & $2(11)$ & $0 \cdot 75^{\star \star}$ & $3(15)$ \\
\hline Previous work load/standard & $0 \cdot 61^{\star \star}$ & $0 \cdot 72^{\star \star}$ & $0 \cdot 60^{\star \star}$ & $2(11)$ & $0 \cdot 66^{\star \star}$ & $2(16)$ \\
\hline Work more tiring & $0 \cdot 74^{\star \star}$ & $0 \cdot 87^{\star \star}$ & $0 \cdot 80^{\star \star}$ & $1(18)$ & $0.67^{\star \star}$ & 1 (18) \\
\hline Relationships with friends & 0.47 & $0.51^{\star}$ & $0 \cdot 57^{\star}$ & $9(3)$ & $0 \cdot 62^{\star \star}$ & $8(7)$ \\
\hline Relationship with partner & $0 \cdot 22$ & $0 \cdot 56^{\star \star}$ & $0 \cdot 30$ & 9 (3) & $0 \cdot 82^{\star \star}$ & $8(7)$ \\
\hline Coping with family demands & $0.52^{\star}$ & $0.56^{\star \star}$ & $0.55^{\star}$ & $7(5)$ & $0.56^{\star \star \star}$ & $5(9)$ \\
\hline Sum total ratings & $0 \cdot 86^{\star \star}$ & $0 \cdot 87^{\star \star}$ & $0 \cdot 82^{\star \star}$ & & $0 \cdot 88^{\star \star}$ & \\
\hline
\end{tabular}

${ }^{\star} \mathrm{P}<0.001 ;{ }^{\star \star} \mathrm{P}<0.0001 . \mathrm{A}=$ Patient/self administration; $\mathrm{B}=$ first interview; $\mathrm{C}=$ second interview. Number in parentheses $=$ number of times item rated positively.

with the least significant coefficients were the items on coping with family demands and the performance of routine domestic activities.

The same four items were the most often reported as changed at first interviews at both three and six month follow up: finding work more tiring; maintaining previous work load; participating in previous leisure and social activities. Similarly, changes in relationships with friends and partners were the least often reported at both three and six month follow up.

Additional detailed evidence of consistency is provided by a comparison of how the number of items rated as a problem, by each patient, changed at each administration, and how this related to the sum totals of the ratings, for each patient, on each occasion. In all cases, increases or decreases in the numbers of items rated was accompanied by proportional increases or decreases in the sum totals. For example, at six month follow up 16 patients remained consistent across both interviews in the numbers of items rated and their sum total ratings. Five patients rated an identical number of items on each occasion, but their sum total ratings showed some variation. The numbers of items selected varied across interviews for 19 patients, and their sum total ratings varied proportionally; in six cases the numbers of items selected and the sum total ratings showed greater variation.

Scatterplot of sum total ratings at six month follow up: first $v$ second interview.
Paired comparisons of the sum total ratings were analysed using the Wilcoxon sign rank test. These showed no significant bias favouring any method of administering the questionnaire at either three or six month follow up, $(P>0 \cdot 1$ for all comparisons).

At three month follow up, before being asked to rate the 10 core items on the questionnaire, patients were initially asked whether they had made a complete recovery. Most patients (eight exceptions), remained consistent across interviews. Discrepancies in the total numbers of responses were accounted for by the varying numbers of patients who felt unable to answer. Comparing self administration $v$ first interview, $\kappa=0.88$ (representing excellent agreement) ${ }^{17}$; first $v$ second interview, $\kappa=0.61$ (representing good agreement); and self administration $v$ second interview, $\kappa=0.90$ (representing excellent agreement). Comparisons were made each time the questionnaire was given between the sum totals of ratings of those answering "yes" to the question on complete recovery with those answering "no". As anticipated, the group answering "yes" had lower sum total ratings (Mann-Whitney $U$ test, $\mathrm{P}<0.0005$ for each calculation).

At six month follow up, after each interview, the therapist assessed whether or not the patient was completely recovered. Comparing the sum total ratings showed lower totals in those assessed as completely recovered (Mann-Whitney $U$ test, $\mathrm{P}<0 \cdot 0001$ ).

At both three and six month follow up, patients were also asked whether they had any other difficulties. Those mentioned most often were symptoms of physical injury which occurred in the same incident as the head injury. Others included loss of libido, difficulties with word finding and numbers, loss of confidence and motivation, no sense of taste and smell, hearing loss, anxiety, inability to relax, mood swings, poor spelling, and vertigo. No single problem was mentioned more often than the least frequently rated items on the questionnaire, those concerning relationships. This suggests that the 10 core items cover an appropriate range.

After both three and six month interviews the therapists also rated their judgement of the level of need for follow up. This was consistent in most cases. The greatest discrepancy at three months was for a patient who had many pre-existing health and social problems, for which she was in contact with other agencies. At six months the greatest discrepancies in judgement were for one patient who, at second interview expressed anxiety about driving related to the accident which caused her injury, and for which she was referred for psychological intervention, and another who seemed much more anxious and depressed at first interview.

Comparisons were made between the clinical judgements at first and second interviews and the sum total ratings at both three and six month follow up. The patients were grouped according to whether they were perceived as needing follow up (the first group being those 
for whom the need for follow up was unnecessary or minimal, the second for whom it was important or essential). As expected, those patients judged as being in need of further follow up had higher sum total ratings than those without such needs (MannWhitney $U$ test, $\mathrm{P}<0.0001$ for each calculation).

The correlation between the sum total ratings derived from the questionnaire and from the RPQ, at first interview, using Spearman's rank coefficient was 0.67 , and at second interview 0.56 (both $P<0.001$ ), confirming validity.

\section{Discussion}

Our results support the use of this new questionnaire as a clinical tool giving an estimate of the overall level to which people experience problems in everyday life after head injuries, including very mild ones. It covers disability, or the practical consequences of any loss of function, rather than impairment. Disability will inevitably be influenced by other factors in addition to the severity of the head injury, including the presence of other injuries, the patient's reaction to their injury, whether or not they have experienced previous injuries, and their personal and social circumstances. ${ }^{18}$ The questionnaire does not attempt to disentangle these influences, it merely asks patients to describe the extent to which they consider that there has been a change in some of the most basic aspects of their everyday lives. Our experience suggests that the questionnaire is adequately sensitive to detect change while being sufficiently short and simple to be useful. The rating scale rather than simple "yes/no" responses extends its range to reflect the disparity in the outcomes of injury for patients, the circumstances of whose injuries vary enormously.

The patients in both samples were unselected and realistically represent the entire range of patients with head injuries attending hospital. Those interviewed were inevitably limited to people it was possible to contact and who agreed to be seen. This results in underrepresentation of younger people, who are more likely to be living in rented accommodation, and for whom telephone numbers were less likely to be available.

The decisions about the timing of follow up were made within the context of delivering and developing a clinical service. At three months after injury, problems are more likely to have become apparent as most people will have returned to work or resumed their usual activities, and, by six months the symptoms of most will have resolved. ${ }^{19}$ The longer the period elapsed since the injury, the greater the likelihood of outcome also being influenced by other factors. ${ }^{18}$

Both studies provide supportive evidence for the adequate reliability of the questionnaire. Sum total ratings have been used in making comparisons, because they reflect the numbers of items rated and offer a basic indication of overall severity, despite the fact that the questionnaire does not use an interval scale. This procedure is well accepted in other scales such as the Barthel activities of daily living index. ${ }^{20}$

To consider the reliability of individual questions in more detail, each was also considered separately. Although showing some variation, the correlations between individual questions on successive administrations were positive. The time between interviews varied, and, for a few patients major changes in their circumstances (the ending of a longstanding partnership, threat to job security), may have affected their responses. The most often reported items at both three and six months were those related to work and leisure, possibly because fatigue is a commonly reported symptom after head injury. ${ }^{15}$ The correlations for individual items at three month follow up (see table), were least consistent for those relating to relationships, but only three patients reported problems with these on each administration. At six months, the least consistent correlations were for routine domestic activities and coping with family demands, which may reflect a tension between expectations on the part of others that the patient should have recovered completely while they are in fact continuing to experience difficulties, but may also be influenced by the low numbers of patients reporting these items.

Whereas it is possible to assess the reliability of the questionnaire, its validity is more difficult to gauge as, so far as we are aware, there are no widely accepted "gold standard" measures to which it could be compared.

Overall comparisons of sum total ratings on the RHFUQ with those obtained on the RPQ indicate a positive correlation. This suggests, unsurprisingly, that those patients who report more postconcussion symptoms or more troublesome symptoms will also tend to rate the changes in their everyday lives as being more extensive. As would be anticipated, the more significant the impairment (as indicated by the $R P Q$ ), the greater the disability. Internal evidence for validity is also provided by the data on responses to the question as to whether patients judged themselves to be recovered, and by the clinical judgements of the therapists about their need for additional intervention.

Validity, and perhaps more importantly, its practical value will be tested in further studies. It should prove of benefit in both research and clinical audit, as we have found in using the questionnaire to evaluate the efficacy of early follow up as part of the OXHIS (results awaiting publication). Through further use, refinements and improvements may be made to enhance both its accuracy and sensitivity.

We thank the patients for being so cooperative; Nicola Moss who helped to devise the original questionnaire; Ann White fo maintaining the Oxford Head Injury Service register; our colleagues for their comments; and the Department of Health for funding the Oxford Head Injury Service as part of its Nationa Traumatic Brain Injury Initiative. 
Appendix: Rivermead head injury follow up questionnaire

\begin{tabular}{|l|l|l|}
\hline \multicolumn{3}{|c|}{ Oxford Head Injury Service } \\
\hline Date: & 6 MONTH FOLLow UP QUESTIONNAIRE & Case No: \\
\cline { 2 - 3 } & & \\
\hline
\end{tabular}

After a head injury or accident some people experience problems which can cause worry or nuisance. We would like to know if you have difficulties with any of the activities listed below. We would like you to compare yourself now with before the accident/injury.

\section{For each one please circle the number closest to your answer}

$$
\begin{aligned}
& \mathbf{0}=\text { no change } \\
& \mathbf{1}=\text { no change, but more difficult } \\
& \qquad \begin{array}{l}
\mathbf{2}=\mathrm{a} \text { mild change } \\
\mathbf{3}=\mathrm{a} \text { moderate change } \\
\mathbf{4}=\text { a very marked change }
\end{array}
\end{aligned}
$$

Compared with before the accidentlinjury,
a) has there been a change in your....?

Ability to participate in conversation with one person Ability to participate in conversation with 2 or more people

Performance of routine domestic activities

Ability to participate in previous social activities

Ability to enjoy previous leisure activities

Ability to maintain your previous work load/standard

Finding work more tiring

Relationship with previous friends

Relationship with your partner

Ability to cope with family demands

b) are you experiencing any other difficulties? Please specify and rate

Would you like a follow up appointment for further advice? $\begin{array}{lllll}0 & 1 & 2 & 3 & 4\end{array}$

1 Hawthorne VM. Epidemiology of head injuries. Scot Med 7 1975;1:23-92.

2 Jennett B, MacMillan R. Epidemiology of head injury. BMF 1981;282:101-4.

3 Ruff RM, Levin HS, Marshall LF. Neurobehavioral methods of assessment and the study of outcome in minor head injury. Fournal of Head Trauma Rehabilitation 1986; head injury.

4 Working Party Report of the Medical Disability Society. The management of traumatic brain injury. February, 1988. 5 Barth JT, Macciocchi SN, Giordani B, Rimel R, Jane JA, Boll TJ. Neuropsychological sequalae of minor head injury. Neurosurgery 1983;13:529-33.

6 Dikmen S, McLean A, Temkin N, Wyler AR. Neuropsychologic outcome at one month post injury. Arch Phys Med Rehabil 1986;67:507-13.

7 Levin HS, Mattis S, Ruff RM, et al. Neurobehavioral outcome following minor head injury: a three center study. $\mathcal{f}$ Neurosurg 1987;66:234-43.

8 Dacey R, Dikmen S, Temkin N, McLean A, Armsden G, Winn R. Relative effects of brain and non-brain injuries on neuropsychological and psychosocial outcome. $f$ Trauma 1991;31:217-22.

9 Bohnen N, Jolles J, Twijnsta MD. Neuropsychological deficits in patients with persistent symptoms six months after mild head injury. Neurosurgery 1992;30:692-6.

10 Rimel RW, Giordani B, Bart JT, Boll TJ, Jane JA. Disability caused by minor head injury. Neurosurgery 1981; 4:221-7.

11 Wrightson P, Gronwall D. Time off work and symptoms after minor head injury. Injury: The British fournal of Accident Surgery 1981:12:445-54.

12 Dikmen S, McLean A, Temkin N. Neuropsychological and psychosocial consequences of minor head injury. $\mathcal{F}$ Neurol

13 Englander J, Hall K, Stimpson T, Chaffin S. Mild traumatic brain injury in an insured population: subjective complaints and return to employment. Brain Inj 1992;6: complain

$\begin{array}{lllll}0 & 1 & 2 & 3 & 4\end{array}$

$\begin{array}{lllll}0 & 1 & 2 & 3 & 4\end{array}$

$\begin{array}{lllll}0 & 1 & 2 & 3 & 4\end{array}$

$\begin{array}{lllll}0 & 1 & 2 & 3 & 4\end{array}$

$\begin{array}{lllll}0 & 1 & 2 & 3 & 4\end{array}$

14 Moss NEG, Crawford S, Wade DT. Post-concussion symptoms: is stress a mediating factor? Clinical Rehabilitation 1994;8:149-56.

15 King NS, Crawford S, Wenden FJ, Moss NEG, Wade DT. The Rivermead post concussion symptoms questionnaire-a measure of symptoms commonly experienced after head injury and its reliability. $f$ Neurol 1995; 242:587-92.

16 Russell WR, Smith A. Post traumatic amnesia after closed head injury. Arch Neurol 1961;5:16-29.

17 Fleiss JL. Statistical methods for rates and proportions. New York: Wiley 1981.

18 Lishman WA. Physiogenesis and psychogenesis in the "post-concussional syndrome". Br f Psychiatry 1988;153: "post-con

19 Evans RW. The post concussion syndrome and the sequelae of mild head injury. Neurol Clin 1992;10:815-47.

20 Collin C, Wade DT, Davis S, Horne V. The Barthel ADL index: a reliability study. International Disabilities 1988; 10:61-3 